\title{
Is there a central pattern generator in man?
}

\author{
LS Illis \\ Consultant Neurologist, Wessex Neurological Centre and Clinical Senior Lecturer in Neurology, Southampton \\ University Medical School, Southampton, UK
}

Below a spinal lesion, even a complete lesion, there exists a relatively normal spinal cord which is potentially capable of central processing of signals, with a normal 'apparatus' of peripheral nerves, muscles, ligaments and limbs which are simply cut off from higher control. The anatomical and physiological properties which form the circuits contributing to control of walking exist but the programming remains poorly understood. After spinal transection, lower vertebrates can perform stepping movements, indicating the integrity of neural mechanisms capable of coordinating muscle activity over several segments. The groups of nerve cells responsible for this integrated activity are sometimes called neural generators and probably exist for each limb; the overall level of activity in respect of these generators is set by continuous descending stimuli from higher levels of the central nervous system. The groups of nerve cells are called the central pattern generator (CPG) or spinal pattern generator. The spinal generator was first proposed in 1914 and refined by Miller and Scott ${ }^{1}$ to involve only three types of neuron: the motoneuron, the Renshaw cell, and the Ia inhibitory interneuron. ${ }^{2}$ In the cat, the CPG can act soon after injury and stepping becomes progressively stronger and may eventually lead to weight-bearing. This stepping may be evoked or enhanced by electrical stimulation ${ }^{3-5}$ and injection of noradrenergic agonists or precursors. ${ }^{6,7}$ However, there appears to be a progressive inhibition of the CPG during ontogeny (the CPG is more readily elicited in a young animal) and phylogeny. It appears that in higher animals the CPG is more heavily inhibited and has not been definitely demonstrated in primates and, until recently, it has not been demonstrated in man.

A recent paper by Hultborn et $a l^{8}$ suggested the possibility of activating the CPG in the marmoset, and there is now some evidence that the elusive and important CPG in man may indeed be capable of being activated. Calancie et $a l^{9}$ reported a 37-year-old man who had suffered an incomplete cervical spinal cord injury 17 years earlier. The patient had suffered his injury while playing American football with immediate loss of movement and sensation below his neck. Investigations showed a compression fracture of the 5 th cervical vertebra which was decompressed. $\mathrm{He}$ gradually recovered partial use of hands and fingers and could make limited movements with his legs but was not able to bear weight. Ten years after the injury he could ambulate in parallel bars a distance of about $3 \mathrm{~m}$ and with 2 months of intensive physical therapy this was increased to about $75 \mathrm{~m}$. In addition, there was some recovery of sensation and he was able to sense when his bladder was emptying. Seventeen years after the injury he started a more intensive physical therapy programme and 1 week after beginning he noticed that within $10 \mathrm{~min}$ of lying on his back and fully extending hips and knees he developed step-like movements of the legs which continued for as long as he remained supine. The movements involved alternating flexion and extension of hips, knees and ankles and could not be stopped by a voluntary effort. Rolling onto his side and flexion at hips and knees produced immediate cessation of movements. Calancie et al ${ }^{9}$ studied this patient comprehensively and came to the conclusion that there was some preservation, although it was extremely limited, of supraspinal activity and an abnormal afferent inflow from the subject's right hip. It is noteworthy that afferent input of the spinal cord is vital in modulating the motor output during cat locomotion and other rhythmic motor activity. During the period of the study (6 weeks) there was improvement in the subject's walking. The maximum distance more than doubled and the velocity was roughly doubled.

Dietz et $a l^{10}$ studied five patients with complete paraplegia, four with incomplete paraplegia and five age-matched normal controls. The complete spinal cord lesion was confirmed by electrophysiological tests. None of the patients could make stepping movements on a stationary surface. In these patients, about 4 to 5 weeks after the accident which caused the injury, they were subjected to training using a treadmill and bodyweight support via a parachute harness connected to a winch. Dietz et al ${ }^{10}$ found that coordinated stepping movements and muscle activity could be induced by these methods without the use of drugs (as had previously been reported by Wernig et al, 1992 $)^{11}$ and were able to record a significant increase in EMG activity.

However, Dietz et al ${ }^{10}$ did not demonstrate that the changes in EMG activity that they found over a period of approximately 6 months were caused by their tread mill training. (There were no paraplegic controls who had no physiotherapy or different physiotherapy). 
Significant changes in spasticity and reflex patterns are to be expected between week 5 and 25 following spinal cord injury, regardless of the type of physiotherapy used. It has always been extremely difficult to evaluate any form of physical therapy, even in a patient with a stable spinal cord lesion. During the sub-acute phase it is even more difficult.

These studies do not absolutely prove the existence of a central pattern generator in man since the total elimination of any supraspinal control would have to be established, but nevertheless these reports are of great interest since they raise the possibility that the loss of supraspinal control may be overcome by appropriate afferent stimulation, training, and the use of intrathecal drug delivery systems. ${ }^{12} \mathrm{~A}$ combination of these factors and spinal cord stimulation which is known to affect spinal reflex activity ${ }^{13}$ is clearly worth further study.

\section{References}

1 Miller S, Scott PD. The spinal locomotor generator. Experimental Brain Research 1977; 30: 387-403.

2 Sedgwick EM. Clinical neurophysiology in rehabilitation. In: Illis LS (ed). Neurological Rehabilitation. Blackwell Scientific Publications: Oxford, 1994, pp 82-102.

3 Shik ML, Orlovskii GN, Severin FV. Locomotion of the mesencephalic cat elicited by stimulation of the pyramids. Biophysics 1968; 13: 143-152.

4 Shefchyk SJ, Jordan LM. Excitatory and inhibitory postsynaptic potentials in $\alpha$-motoneurons produced during fictive locomotion by stimulation of the mesencephalic locomotor region. J Neurophysiol 1985; 53: 1345-1355.

5 Shefchyk SJ, Jordan LM. Motoneuron input-resistance changes during fictive locomotion produced by stimulation of the mesencephalic locomotor region. J Neurophysiol 1985; 54: 1101-1108.

6 Forssberg H, Grillner S. The locomotion of the acute spinal cat injected with clonidine i.v. Brain Res 1973; 50: 184-186.

7 Barbeau H, Chau C, Rossignol S. Noradrenergic agonists and locomotor training affect locomotor recovery after cord transection in adult cats. Brain Res Bull 1993; 30: 387-393.

8 Hultborn H, Petersen N, Brownstone R, Nielsen J. Evidence of fictive spinal locomotion in the marmoset. (Callithrix Jacchus) (abstract). Soc Neurosci Abstr 1993; 19: 539.

9 Calancie B et al. Involuntary stepping after chronic spinal cord injury. Brain 1994; 117: 1143-1159.

10 Dietz V, Colombo G, Jensen L. Locomotor activity in spinal man. Lancet 1994; 344: 1260-1263.

11 Wernig A, Muller S. Laufband locomotion with body weight support improved walking in persons with severe spinal cord injuries. Paraplegia 1992; 30: 229-238.

12 Barbeau HJ, Julien C, Rossignol S. The effects of clonidine and yohimbine on locomotion and cutaneous reflexes in the adult chronic spinal cat. Brain Res 1987; 437: 83-96.

13 Illis LS. Recovery in the central nervous system and the experimental background of central functional stimulation. In Illis LS (ed). Spinal Cord Dysfunction, Vol III. Oxford University Press: Oxford, 1992, pp 9-37. 